World War II $(p=.17)$ or the post World War II $(\mathrm{p}=.33)$ figures.

One possible explanation for the lack of symmetry in assertions is that, when the $S$ evalutes a public figure, he does so on the basis of attributes that are available to anyone evaluating that figure, including the figure's contemporaries. Since figures that are positively evaluated have positive attributes and figures that are negatively evaluated have negative attributes, "reality" demands that the assertions made about positive figures be positive and assertions made about negative figures be negative. If one combines the "reality" demands with the necessity for congruity, the obtained results are explicable. Congruity forces and "reality" both lead to a negative assertion in the case of a positive source and a negative concept. In the case of a negative source with a positive concept congruity demands a negative assertion, while "reality" demands a positive assertion. Since "reality" cannot be completely denied even by a negatively evaluated figure, the result in this case, is a less negative assertion. In general, to the extent that the source is more positive than the concept, both "reality" and congruity tend to increase the negativity or decrease the positivity of the assertion. To the extent that the source is less positive than the concept, congruity works in the direction of negativity, while "reality" works in the direction of positivity; hence, the obtained asymmetry with positive sources less charitable than less positive sources.

This finding would seem to bear on the question of incredulity. What the data suggest is that it would be more believable for a positive source to reject a negative source than vice versa. In fact, while the present finding of asymmetry was unanticipated, Leaf, Kanouse, Jones, \& Abelson (1968) have, in the context of analyzing the believability of sentences, reported similar findings. Looking at balance effects of subject-verb-object sentences, they found that: "Predicate balance represented the largest observed balance effect [p. 424]." That is, all things being equal, sentences in which "good" people were the object of positive verbs and sentences in which "bad" people were the object of negative verbs were more believable than vice versa.

On the whole, this study demonstrates that the assumed assertion one person will make about another is systematically responsive to the evaluative sign of both figures in the pair and the direction of the assertion (i.e., A about B vs B about A). Further, it would suggest that congruity theory should be extended

to take into account: (1) changes in the perceied assertion as a dependent variable that might operate in addition to or as an alternative to attitude change on the source/concept and (2) determinants of incredulity beyond degree of incongruity as presently defined.

\title{
REFERENCES
}

LEAF, W. A., KANOUSE, D. E., JONES, J. J., \& ABELSON, R.P. Balance, character expression, and the justice principle: An analysis of sentence evaluations. Proceedings of th 76 th Annual Convention of the American Psychological Association, 1968 , 423-424.

OSGOOD, C. E., \& TANNENBAUM, P. H. The principle of congruity in the prediction of attitude change. Psychological Review, 1955, 62, 42-55.

\section{Perceptual recognition and guessing behavior by normal and educable retarded children*}

\author{
LARRY M. RASKIN. LOUELLA J. FONG, and KATHRYN N. BLACK \\ Purdue University, Lafayette, Ind. 47907
}

This study was concerned with the recognition of fragmented (or incomplete) stimulus forms by normal and educable-retarded children (EMRs) at two MA levels. A series of 12 slides was presented, and the number of brief exposure periods required to make a correct identification was recorded. The analyses of the results showed that younger MA Ss need more exposures to identify these forms. While there were no effects of IQ, the EMRs made many more incorrect guesses than did the normals, and the younger EMRs guessed more than all other children.

The present study was concerned with the recognition of tachistoscopically presented fragmented line drawings by two MA levels of normal and educable-retarded children (EMRs). The number of 10-msec exposures required for correct identification of each picture, as well as incorrect responses, was recorded. The use of the brief exposure technique was based on the finding of Haber and his coworkers (e.g., Haber, 1965; Haber \& Hershenson, 1965; Haber \& Hillman, 1966 ; Hershenson \& Haber, 1965) that the probability of correct identification increases with repeated presentations. Thus, it provides a measure of the amount of experience necessary to establish a percept, a process which may be influenced both by level of intellectual functioning (normal or EMR) and intellectual development (MA). In conjunction with the above, the response styles of the two IQ populations were examined.

* The authors wish to thank the Tippecanoe School Corporation for their cooperation in this research project. Authors Raskin and Black are at the Department of Child Development and Family Life, Purdue University, Lafayette, Indiana 47907. Professor Fong is now at Western Kentucky State University. Reprints are available from the first author. Parts of this paper were presented at the Eastern Psychological Association meeting, Atlantic City, New Jersey, April 1970.

\section{SUBJECTS}

Forty-six educable mentally retarded children (EMRs) and 46 normals, 23 kindergartners and 23 third graders, served as Ss. IQ and MA scores for all children were obtained with the Peabody Picture Vocabulary Test, Form B. EMRs were divided into older and younger groups at the median MA of 7-0. Mean MA, CA, and IQ for the older group of EMRs were $8-8,14-0$, and 70.7 , while the younger EMRs had mean MA, CA, and IQ scores of $5-8,9-6$, and 68.3 , respectively. The older normals (third graders) had mean MA, CA, and IQ of 8-11, 9-0, and 98.2, while those of the kindergartners were $5-11,6-0$, and 98.1.

\section{MATERIALS}

A pretraining series of forms was developed. Five fragmented white ink drawings (leaf, ship, arm and fist, flag and flagpole, key) were shown on $3 \times 5$ in. pieces of black construction paper. A test series composed of 12 slides was also created. Each slide contained a single fragmented white drawing on a black background. (Figure 1 shows these in a reversed black-white relationship for ease in looking at on the printed page.) The slides were shown with a Kodak Carousel slide projector equipped with a tachistoscopic shutter. 

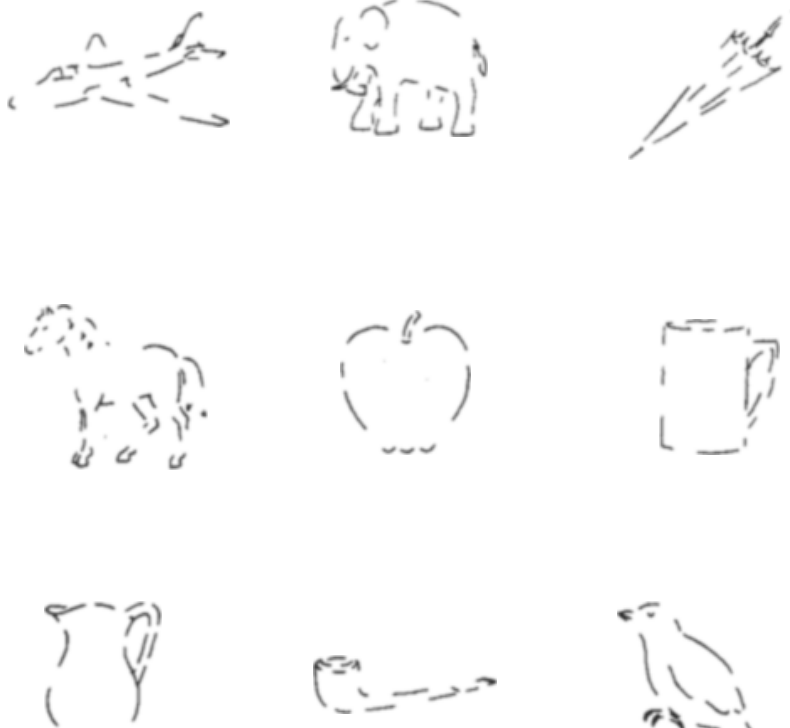

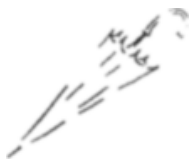

\section{,}
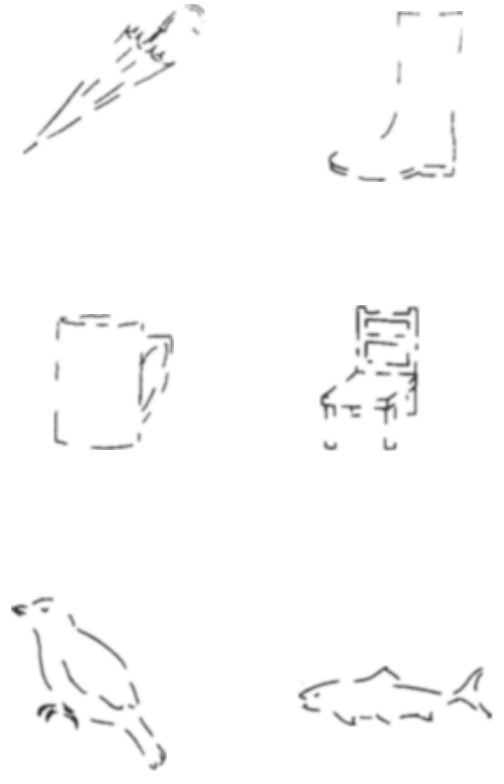

Fig. 1. Stimulus forms used in the recognition and retention tasks.

\section{PROCEDURE}

The child was first shown and asked to identify the example cards. He was then told that he would see some more incomplete pictures on the screen and that these would be shown very rapidly. Three different random orders were used to present the test series, and each child was assigned randomly to one of these orders. He was urged to respond as soon as he thought he could identify each picture. Each slide was shown in exposures of $10 \mathrm{msec}$, and the interexposure interval was 5 sec. The $S$ was seated $7 \mathrm{ft}$ from the screen. If the child could not identify the slide, he was asked to look carefully and it was shown again. If an incorrect response was made, the $E$ said, "Not quite. Let's look again carefully. Ready?" If any child was unable to identify correctly a slide following 10 exposures, it was projected continuously. If he still was unable to identify the slide, he was given the answer, asked to repeat the label, and then asked if he could see the object. Following a correct identification, the child was verbally praised and prepared to view the next slide. The child's response following each exposure was recorded.

$$
\text { RESULTS }
$$

The mean number of exposures to set recognition by all groups was 24.8 for the older normals, 34.2 for the younger normals, 25.8 for older EMRs, and 30.4 for the younger EMRs. A 2 by 2 analysis of variance with main factors of $I Q$ and $M A$ produced a significant MA effect $[F(1 / 88)=6.83, \quad p<.05)$. This showed that the older MA children, regardless of intellectual level, recognized the fragmented pictures in fewer exposures than did the younger MA ones. Neither the main effect of IQ nor the MA by IQ interaction was significant, showing that recognition scores were independent of IQ at each age level.

Since there were no differences in rate of recognition among EMRs and normals at each age level, the data were combined to see if the series was more difficult for the younger MA Ss. Thirty-five of these 46 younger children could not recognize at least one of the slides in their 10 exposures; 25 of the 46 older MA children could not do so. This was a significant difference $\left(x_{1}^{2}=4.78, p<.05\right)$.

The proportions of guessing errors to total errors (guessing plus no response) were analyzed. The older EMRs guessed 127 times out of 304 total incorrect responses. The proportions for the younger EMRs, older normals, and younger normals were $220 / 423,98 / 304$, and $156 / 511$, respectively. A comparison of these proportions (Ferguson, 1966) showed that the older EMRs made significantly more guesses than did the older normals $(z=3.4, p<.001)$, the younger EMRs guessed significantly more than the younger normals $(\mathrm{z}=6.7, \mathrm{p}<.0001)$, and the younger EMRs guessed more frequently than the older EMRs $(z=2.72, p<.01)$. However, there was no difference between the two groups of normal children in proportion of guessing to omission errors.

\section{DISCUSSION}

This experiment found that there were major differences between the younger and older MA groups in series recognition, but no differences were found between the EMRs and normals of comparable MA. However, the effect of intellectual functioning was evident when the types of errors were analyzed; the EMRs made significantly more guessing errors than did the normals. This latter finding might indicate that the EMRs had difficulty withholding their verbal responses in the face of uncertainty or perhaps even obvious mistake. A number of investigators have noted the apparent lack of inhibitory control in the retardate (e.g., Luria, 1963), and one of the present authors (Raskin, 1969) has reported a finding in the perception of apparent movement by EMRs that might be interpreted in terms of the lack of inhibitory perceptual learning.

In the present study, there were some methodological limitations owing to its exploratory nature. For example, while it was thought that 10 exposures of each stimulus slide would be adequate for the children to identify the forms, it appears that, for some forms, a greater maximum would have been advantageous. Also, with a 10-msec exposure, the shortest possible with the shutter used, some of the forms were too easy while others were too difficult. However, the technique developed by Haber and his coworkers is one that, with careful control, should be very useful in studies of perception in children.

\section{REFERENCES}

FERGUSON, G. A. Statistical analysis in psychology and education. (2nd ed.) New York: McGraw-Hill, 1966.

HABER, $R$. $N$. The effect of prior knowledge of the stimulus on word recognition processes. Joumal of Experimental Psychology, 1965, 69, 282-286.

HABER, R. N., \& HERSHENSON, M. The effects of repeated brief exposures on the growth of a percept. Journal of Experimental Psychology, 1965, 69, $40-46$.

HABER, R. N., \& HILLMAN, E. R. The effect of repetition on the perception of single letters. Perception \& Psychophysics, 1966, 1, 347-350.

HERSHENSON, M., \& HABER, R. N. The role of meaning on the perception of briefly exposed words. Canadian Journal of Psychology, 1965, 19, 43-46.

LURIA, A. R. Psychological studies of mental deficiency in the Soviet Union. In N. R. Ellis (Ed.), Handbook of mental deficiency: Psychological theory and research. New York: McGraw-Hill, 1963. Pp. 353-387.

RASKIN, L. M. Long-term perceptual memory in normal and educable retarded children. American Journal of Mental Deficiency, 1969, 73, 903-905. 